\title{
A CRITICAL-HOLISTIC APPROACH TO THE PLACE-SPECIFIC GEOGRAPHIES OF INHABITED RIVER ISLANDS ON THE RURAL- URBAN FRINGE OF INLAND CHINA
}

[Received April 28th 2020; accepted June 23rd 2020 - DOI: 10.21463/shima.14.2.11]

$$
\text { Hong Gang }
$$

Sun Yat-sen University, China <zhouhongg3@mail.sysu.edu.cn>

\begin{abstract}
River islands have been a relatively marginal topic in Island Studies literature for diverse geographical and disciplinary reasons. Critically engaging with past literature, this article is an attempt to examine this hitherto neglected island type based on the local experiences of inhabited river islands located on the rural-urban fringe of inland China. Through a comparative analysis of Chongming Island (Shanghai), Baguazhou (Nanjing) and Dongzhou Island (Hengyang), the article proposes a critical-holistic approach to understanding the place-specific geographies of these river islands. It is argued that inhabited river islands on the rural-urban fringe of inland China are characterised by a geography of paradox insofar as they are at once super-connected to mainland environments and utterly unconnected with kindred islands in the fluvial system. The former trait implies greater assimilation, with uncertain consequences, for such islands, while the latter indicates the virtual impossibility of them forming larger non-mainland collectivities. It is proposed that identity culture - rather than identity politics - is a more viable, and also urgently needed alternative for these islands in face of mass homogenisation. It is also proposed that studying locations that Island Studies may have cast as atypical presents several benefits for the interdisciplinary field.
\end{abstract}

KEYWORDS: River islands; Island Studies; rural-urban fringe; inland China; island imaginary

\section{Introduction}

Inhabited river islands have been a relatively marginal topic in Island Studies literature for diverse geographical and disciplinary reasons. This article is an attempt to examine this hitherto neglected island type by concentrating on the place-specific geographies of one particular sector: inhabited river islands on the rural-urban fringe of inland China. Like nonriverine islands, the geographies of river islands are place specific. Even in a single waterway like the River Thames there are a vast array of river islands, large and small, fluvial and estuary, wild and historical, inhabited and unpopulated (Vickers, 2012: 7-10). What is pertinent to the particular context of this research is that there is a spectrum of inhabited river islands with an urban-rural continuum. At one polarity there are ultra-urbanised river islands that are so integrated into cities that their island identity is partly obscured (eg Ersha and Shamian, Guangzhou; Manhattan, New York; Île de la Cité, Paris). At the other polarity, river island communities are located in rural areas, perhaps closer to the stereotypical 
imaginary of remote and underdeveloped backwaters (eg Sviyazhsk, Russia, the chars of the Brahmaputra River in Assam, India and chars in Bangladesh). ${ }^{1}$

The three inhabited river islands addressed in this case exist, to varying degrees in the "boundary zone outside the urban area proper where rural and urban land uses intermix", that is, the "rural-urban fringe" of inland China (Planningtank, 2017: online). ${ }^{2}$ This ambiguous location exposes them to intense spatial reconfigurations resulting from the waves of relentless urban expansion in inland China that started around the mid-20oos, often resulting in the coexistence of multiple island imaginaries and related tensions.

One of the motivations for this article is the recent, modest, development of research on Chinese islands in Island Studies literature, which relies heavily on the model of saltwater islands in the coastal and archipelagic areas of eastern and southern China. After a brief clarification of the concept of river island and some terminological confusions, I will undertake a critical review of recent Chinese Island Studies so as to reveal the complex circumstances of Island Studies' approaches to Chinese islands. After this, I will take a brief detour to summarise the tendency in physical geography to treat river islands as 'living fossils' instead of lived communities in order to emphasise the necessity of studying inhabited river islands from a socio-cultural perspective. The main body of the article is a critical-holistic analysis of three inhabited river islands on the rural-urban fringe of inland China. The conclusion summarises the place-specific geographies of these islands and proposes several potential benefits of studying them. It is argued that inhabited river islands on the rural-urban fringe of inland China are characterised by a geography of paradox insofar as they are at once super-connected to mainland environments and utterly unconnected with kindred islands in the fluvial system. The former trait implies greater assimilation, with uncertain consequences, for the island, while the latter a virtual impossibility to form larger non-mainland collectivities. Considering the place-specific geographies of these islands, identity culture rather than identity politics seems like a more viable and, arguably, urgently needed alternative for them in face of mass homogenisation.

\section{The Concept}

Some conceptual and terminological confusions should be clarified first. I follow most, if not all, literature from various branches of physical geography, especially geomorphology, in defining a river island as a land mass within a river channel that is separated from floodplains by water on all sides, which exhibits some stability and which remains exposed during the river's bankfull stage. The relative stability of river islands sets them apart from bars which may be periodically submerged (Osterkamp, 1998; Wyrick and Klingeman, 2011). The stability of river islands is due to the fact that they exist not only in an "interflood time period", but also remains exposed after the "next high flow" occurs (Wyrick and Klingeman, 2011). Some studies note that vegetation is a general - but not necessary - indicator of the status of a river island. I am also aware of the existence of river islands whose place-specific geographies defy this physical definition modelled on insular stability. One of the notable examples is to be found in chars in South Asia. Their capricious geographies, totally at the

\footnotetext{
${ }^{1}$ For reports and research on the remote rural communities of chars in South Asia see Coupe (2001); Misra (2011); Lahiri-Dutt (2014); Kenward et al (2015); Pritchard et al (2015).

2 Shanghai's administration of Chongming Island is undoubtedly outward-looking and cosmopolitan in comparison with other Chinese cities but considering its relative distance from a sea coast, it is still conceptualised as an inland city in a broad sense.
} 
whim of the Monsoon Rivers, challenge fixed conceptions of land-water boundaries and land ownership (Lahiri-Dutt, 2014). However, the kinds of river islands examined in our case is conceptualised more in line with the insular stability model considering their relative presence throughout recorded history.

Disciplinary differences in the usage of terms designating islands in fluvial systems should be clarified. According to existing literature on the subject, three terms have emerged to designate the island type: fluvial island, riverine island and river island. The first is used frequently, mainly in the various branches of physical geography such as geomorphology and biogeography. The second appears occasionally in studies of the social deprivation facing many island communities in South Asia. The last term, which is used widely by nonspecialists, is seen only sporadically in the literature, perhaps because within the fields of Humanities and Social Sciences there are very limited studies of river islands per se (Grydehøj, p.c, 2018). In this article, I use the term river island, instead of its more technical equivalents, in order to appeal to a more interdisciplinary and cross-cultural readership.

\section{Maritime Islands as the Dominant Model in China}

The study of islands in the Sinophone world has developed modestly since the mid-2oios. This increased interest in Chinese nissology is best embodied by (though not confined to) a 2017 thematic section devoted to the study of Chinese islands in the Sinophone world in Island Studies Journal. Except for two debates over the political economy of the Chinese and American presence in the Caribbean and the Pacific (McElroy and Bai, 20o8; Crocombe, 2009), most of the literature on Chinese islands was produced after 2015. These publications share a tendency to study Chinese islands and archipelagic spaces in their own right, though the extent to which the island becomes an approach rather than an object of study varies. The areas this research has covered have been largely maritime, that is, many of them have focused on archipelagic or coastal spaces in the Pacific Ocean, covering the East and South China Sea (Su et al, 2017; Yue et al, 2017; Qiu et al, 2017; Lee et al, 2017; Yu et al, 2017; Chao and Chao, 2017; Hong, 2017; Li, 2016; Hayward, 2016; Leung et al, 2017; Kwong et al, 2017; Ni et al, 2017; Ou and Ma, 2017). There are a few exceptions. For instance, Su's (2017) examination of the correlation between islandness and Guangzhou's outward-looking tendency is undertaken in the context of Islamic diaspora dwelling among highly urbanised Pearl River archipelagic areas. The "smart eco-city" of Dongtan, Chongming Island has also been analysed in a sharp criticism of the exploitation of island spatiality for "secessionary enclaves” often resulting in illusory sustainability (Grydehøj and Kelman, 2016).

Overall, island tourism and community development constitute the main topics of the aforementioned research, complemented by other concerns such as the formation and morphology of island cities and the political, social and cultural tensions that this process involves (Lee et al, 2017; Yu et al, 2017; Ou and Ma, 2017; Hayward, 2016; Su et al, 2017). Aside from issues related to island tourism, there is another strand of research that tilts heavily towards the urban dimension of Island Studies. In this trend, the region that has gained most attention is probably the Pearl River Delta area embracing Guangdong, Hong Kong and Macau, possibly because of its status as the most urbanised archipelagic area in China. These bodies of research are often conducted in a manner that seeks to identify how islandness, be it manifested in maritime or riverine environments, has configured, influenced and defined city formation and morphology in the region (Su, 2017; Li, 2016; Ni et al, 2017; Kwong and Wong, 2017; Leung et al, 2017; Hong; 2017). 
The aforementioned research publications on islands in the Sinophone world are recent and a few general patterns can be recognised, one of which is particularly important. With some exceptions, these bodies of research mainly focus on the archipelagic and coastal areas in or near the East and South China Sea. Admittedly, this preference is not groundless; it is a fact that the majority of Island Studies around the world focus on maritime islands and these two seas form the largest section of maritime China. However, culturally speaking, anyone with a cursory knowledge of China's border history could spot the trace of the routes taken by Western imperialists into the Oriental land, with Zhoushan and the Pearl River Delta being two of the most prominent entry points (Ueda, 2014: 88-90, 423-424). In this body of research, these land-sea interfaces are in many stances treated as effective conduits in approaching Chinese islandness partly because of their economic prosperity, political fluidity and cultural hybridity. They are interpreted as liberal spatialities facilitating international tourism, engendering alternative political identities and enabling urban and cultural fragmentation. This tendency, though justified from a real-world geographical basis and productive in connecting the imaginary continental China to the "sea of islands", has come at the price of losing sight of the vast number of river islands hidden deep in the Chinese hinterland.

Nevertheless, one should guard against the temptation to exaggerate the cultural-political import of the trend. If history of colonial penetration could contestably function as an "ultimate cause", several "proximate causes" are perhaps more empirically relevant (Diamond, 2017: 438). Much of the literature that I have reviewed stemmed from a 2016 conference held in Hong Kong and a 2017 Island Studies Journal special section largely derived from that conference. Personal connections established on these occasions play an indispensable role in making these publications possible. A counterexample could be given. Xiamen was also a colonial entry point and it also has a top university by Chinese standards (Xiamen University). However, the island city was not a focal point in the literature simply because no researchers from there happened to have engaged with Island Studies as such. Moreover, another reason that researchers have focused on these coastal regions rather than inland ones may be that they happen to be the locations of major academic institutions sponsoring research concerning nearby islands. But unchecked speculation is tricky; it brings us to the question regarding whether colonial history or contingent factors are more relevant. How one answers the question is dependent on how far back one wants to rewind so as to look for deeper, unconscious, and also reasonable causes.

With a few exceptions, river islands have thus far failed to draw significant attention from researchers studying Chinese islands. It can also be argued that river islands per se have not been considered a worthy subject for many Island Studies scholars. Many cultural imaginations and representations of islands have been undertaken with regard to images of saltwater rather than freshwater islands. Accordingly, Island Studies, as an interdisciplinary field of enquiry, has developed almost largely within "an assumed context of saltwater geographies" (Hay, 2013). This lack of attention is, to some degree, justifiable. Hay (2013) attributes this to the perception that freshwater islands, in general, including river islands, are often too integrated within urban surroundings to exhibit significant aspects of (what Island Studies conceives of as) islandness. Another reason may be that due to their proximity to non-island environments, it is difficult to find island-specific cultures or species on them. Within Island Studies' commitment to studying islands on their own terms, river islands in general may suggest themselves as being less island-like than their maritime counterparts, 
though few would have difficulty still conceptualising them as islands ${ }^{3}$. Moreover, the research landscape reflects as much about its subject as about its object. Island Studies is overtly interdisciplinary, which means, among other things, that most self-identified Island Studies scholars come from other disciplines, often with a relatively established area studies tradition behind them. Some notable areas they focused on before taking on a more or less stable interest in islands per se, include the Pacific, the Caribbean, the Mediterranean and the Atlantic; none of these regions is riverine. Therefore, from the standpoint of Island Studies itself, it is hardly surprising that the dominant model of islands should be one associated with the sea.

Nonetheless, a shift of perspective is beneficial for a more cross-cultural understanding of this oversight. Globally, river islands exist in great numbers, particularly so in countries consisting of vast continental landmasses (eg India, China, Brazil, and America) where vital fluvial systems often form key economic, political and cultural channels. Culturally speaking at least, to ignore (or neglect) these geographical entities is to succumb to the very Western stereotype that Island Studies sets out to deconstruct. In short, an obsession with the sea can be both liberating and fetishising when it comes to studying Chinese islands.

\section{Living Fossils or Lived Communities?}

While river islands have been a marginal topic in Island Studies, there has been a persistent enthusiasm in studying them in branches of physical geography, notably from geomorphology. The details of this do not concern us for the particular purpose of this article but several patterns can be summarised so as to pave the way for a socio-cultural approach towards studying river islands. For one thing, researches from geomorphology concentrate on uninhabited river islands. They are treated as living fossils, that is, fluvial organisms that have "remained essentially unchanged from earlier geologic times" and whose kindred entities in the fluvial system are usually subject to pronounced changes effected by heavy human pressure (Merriam-Webster.com Dictionary, 2020).

This can be seen in a typical geomorphological definition of river islands as "land masses within river channels" that are "separated from floodplains by water on all sides", exhibiting some stability and remaining exposed during the river's bankfull stage (Wyrick and Klingeman, 2011: 814). In keeping with this definition, existing geomorphological studies of river systems tend to foreground the tension between island formation and island elimination. As Wyrick and Klingeman (2011) reveal: "human influences on rivers and their channels have been severe... As part of such manipulations, islands have been eliminated or connected to adjacent floodplains. Thus, fluvial islands have disappeared from many river reaches" (ibid: 821). Also see Osterkamp (1998), Picco et al (2013), Picco et al (2014), Wintenberger et al (2015), Gurnell and Pett (2002) and Francis et al (2009) for discussion of the tension in diverse manifestations.

In contrast to unpopulated river islands studied by physical geography, Island Studies, almost without exception, addresses islands that are populated, although their population may be small. In this regard, there is no way to treat them as living fossils. They can only be approached as human communities located at the intersection of intense spatial relations. In

3 Ultra-urbanised ones such as Hong Kong Island and Manhattan may be different (Hayward, 2015). Their islandness tends to be obscured sometimes due to their almost total integration into urban environments. 
the following analysis, I will seek to demonstrate the value of studying river islands as such by examining the place-specific geographies of three inhabited river islands on the rural-urban fringe of inland China: Chongming Island (Shanghai), Baguazhou (Nanjing), and Dongzhou Island (Hengyang).

\section{Three Inhabited River Islands on the Rural-urban Fringe of Inland China}

\section{a. Chongming Island}

Chongming is the largest alluvial island in the world and also the third largest island in China (dwarfed only by Taiwan Island and Hainan Island) (Zhan et al, 2019). Over 1400 square kilometres in size, the island is located at the easternmost mouth of the Yangtze just as it joins the East China Sea. Though it has a relatively fuzzy status between being a freshwater and saltwater island, most literature in China tends to portray it in relation to the Yangtze. The island, the majority of which is administered by the Shanghai municipality, is only $45 \mathrm{~km}$ from the mainland section of the megacity. The proximity has been reinforced by the building of a 1.2-kilometre cable bridge connecting it to mainland Shanghai. Once home to farmers and fishermen, it has been subjected to a series of state-led green developments (with varying outcomes) during the past decade or so, such as currently failed eco-city constructions and the wetland preservation program now in progress at Dongtan (Solimine, 2013). Of the three islands presented here, Chongming has received the most significant media and scholarly attention at both national and international levels.

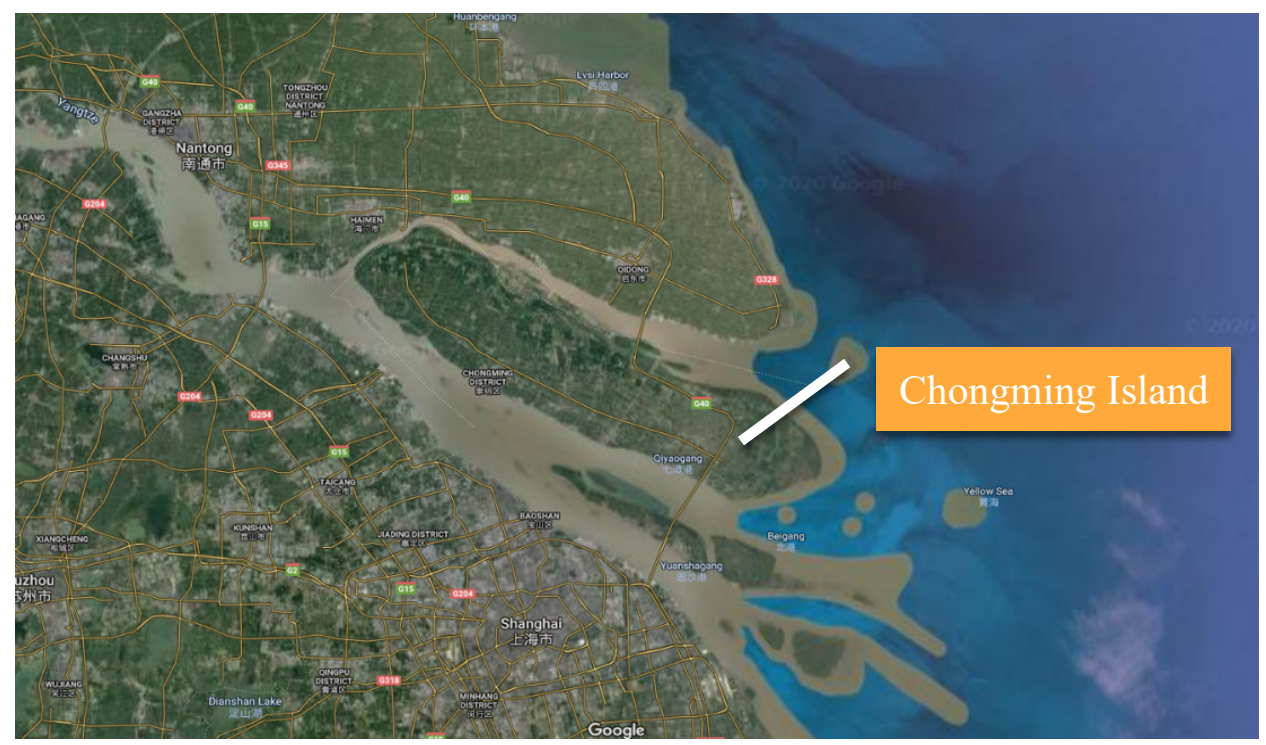

Figure 1 - Satellite image of Chongming Island at the intersection of the Yangtze and East China Sea. (Source: Imagery @2020 TerraMetrics, DigitalGlobe, CNES/Airbus, Digital Globe, Map data @2020 Google)

Salient factors concerning Chongming's identity include its relatively large size, its proximity to the sea, and its accessible distance from a highly urbanised megacity. Combinations of these factors have given rise to three prominent relations: its relation to a fluvial ecosystem; its relation to a marine ecosystem; and its relation to mainland urban centres. The separation of 
these relations only serves intellectual clarity; in reality, they coexist in intense dynamism.

As a result of the above, several place-specific spatial practices have emerged historically; including an agricultural and fish supply base for Shanghai; a pioneer of state-planned ecological modernisation featuring waterbird and plant diversity; a natural reserve impacted by human disturbance (such as land reclamation and animal grazing); and a touristic getaway from and for mainland Shanghai (Ma et al, 2019; Li et al, 2019; Zhan et al, 2019; Chi et al, 2020; Zheng et al, 2016; Wang et al, 2015; Wang et al, 2013; Fan and Zhang, 2012; Liu et al, 2019; Cui et al, 2014; Xie et al, 2019). These spatial practices overlap and clash with each other, resulting in a series of tensions. Should Chongming be an eco-island for Shanghai or an original wetland for itself? Should it be a river island for domestic services or an island oriented towards riversea joint transport between China and countries on the other side of the Yellow Sea, notably Japan. How does one reconcile conflicting interests such as agricultural production and ecotourism economy, and the promises of state-led ecological modernisation and local environmental and community concerns (Xie et al, 2019)?

\section{b. Baguazhou Island}

Baguazhou is the third largest island in the Yangze (Cui and Yan, 2020). About 56 square kilometres in size, the quasi-rural island is located in the northwestern part of Qixia District, Nanjing municipality, a major city in the lower stretch of the Yangtze. Unlike Chongming, the island is unquestionably fluvial in nature. It is a country-level island consisting of seven villages with a total population of about 33,00o long-term residents administered by a single community committee (Cui and Yan, 2020). In the region the Yangtze is usually perceived as the most important geographical reference line, diving the city evenly into the north and south banks. Whereas the south bank has always been the heart of Nanjing, the formerly rural north bank has been subjected to relentless waves of urban expansion since the mid-20oos (Wu, 2019 and Zhou, 2020, p.c). Baguazhou, perched in the Yangtze in proximity to the north bank, had developed and is still perceived by many locals as a vegetable market for mainland Nanjing and is now incorporated into the North Bank New District (Song et al, 2017). The building of the No. 2 Yangtze Bridge in 2001 facilitated the development of tourism on the island and its incorporation (though not total integration) into mainland Nanjing across the river (Wu et al, 2004; Zhou, 2020, p.c). Despite the abundance of local media and scholarly attention, Baguazhou is less known at national and international levels. Salient factors constituting Baguazhou's identity include its medium size, its rural status, and its relative embeddedness in an urbanised city. Combinations of these factors have given rise to three prominent relations: its relation to a fluvial ecosystem, its relation to a mainland urban centre on the south bank and to a mainland rural area on the north bank.

As a result, several place-specific spatial practices have emerged historically. These include a traditional rice supply base for mainland Nanjing; an innovated agricultural produce supply base for mainland Nanjing; a vulnerable piece of land defending itself against flooding; and a green tourist space signifying a modern and sustainable future of the city (Bi, 2003; Hong et al, 1999; Chen et al, 2009; Qin and Li, 2019; Wu et al, 2004). These spatial practices also overlap and clash with each other, resulting in a series of tensions. How to accommodate significant industrial development along the banks with the ecological wellbeing on and near the island? How to negotiate the island community's economy and everyday conveniences and its potential sewage and wastewater pollution to the Yangtze? Does the building of the bridge connecting the island and the more urbanised south bank provide opportunities for the local community or disrupt its ecological and social equilibrium? 


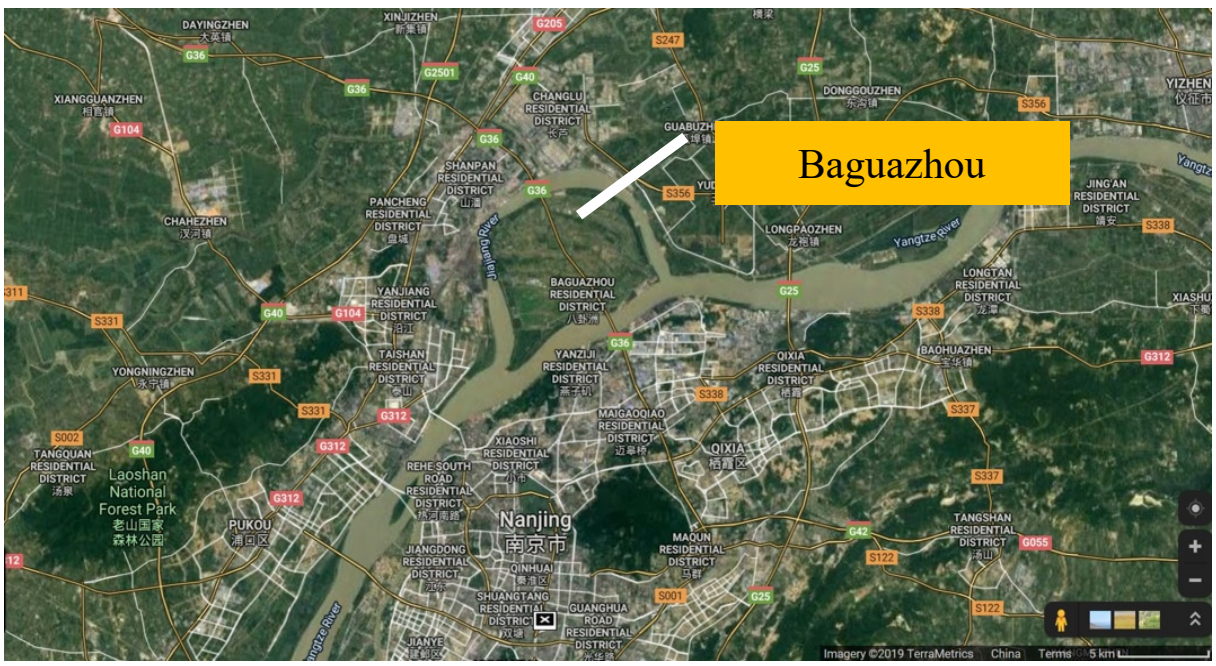

Figure 2 - Satellite image of Baguazhou in the Nanjing section of the Yangtze. (Source: Imagery @2020 TerraMetrics, DigitalGlobe, CNES/Airbus, Digital Globe, Map data @2020 Google)

\section{c. Dongzhou Island}

At 2000 metres long and 200 metres wide, Dongzhou is a much smaller and more obscure inhabited river island than the two described above. The island is located in the Hengyang section of Xiangjiang River, a major tributary of the Yangtze threading through many cities in the landlocked province of Hunan. Dongzhou's status of being a river island is unquestionable considering Xiangjiang River's inland location. The island used to be administered by a quasirural district government of Hengyang municipality before being incorporated within the more urbanised old central district, due to a major tourism project undertaken on it during the 2010s. Dongzhou's proximity to the urban centre has also been reinforced by the building of an antique-style bridge connecting the landed town on the east bank and the island. Though always embedded uncomfortably at the urban-rural juncture of the landed city and never as autonomous as its more insulated counterparts, the island used to be home to a local village with its own primary school and a community living a littoral life consisting of smallscale vegetable growing and fishing. Post-2010, the city government decided to turn it into a tourist park by heritagising its long neglected historical relics into a local landmark in an archaic style with a touch of modernism. The island village, along with its school and community, was relocated wholesale on to the mainland. Dongzhou has received considerable media and scholarly attention due to tourism branding campaigns over the last decade. However, due to its tininess, inland location and the affiliated city's lower-tier status, there has been no wider media coverage of it beyond the local level.

Salient factors concerning Dongzhou's identity include its tiny size, its inland location, and its affiliation with a lower-tier city. Combinations of these factors have given rise to three prominent geographical relations: its relation to a fluvial ecosystem; its relation to a mainland urban centre on the west bank; and its relation to a mainland quasi-rural area on the east bank. As a result of these, several place-specific spatial operations have occurred on the island. These include the reconstructed Chuanshan Academy, a school founded by a Qing Dynasty official near the end of the 19th Century commemorating Wang Chuanshan, a nationalist 


\section{Gang - Chinese River Islands}

intellectual/bureaucrat. Originally built on the mainland, the school was relocated onto the island seven years later because its littorality and relative insularity were considered not only suitable for quiet learning but also compatible with some traditional Chinese intellectuals' ideal of secular hermitage. Other heritage locations with varying degrees of visibility include a prison where the Japanese army used to torture and kill Chinese military captives near the end of the Second World War; a quasi-rural community relying on small-scale agriculture and fishery; and an eco-cultural tourism centre made possible by a governmental project at the cost of a total removal of its original village and inhabitants from the island (Platt, 2007: 1-30; Li, 2015; Li, 2011; Yi, 2011; Zou, 2013; p.c with anonymised islanders, 2018).

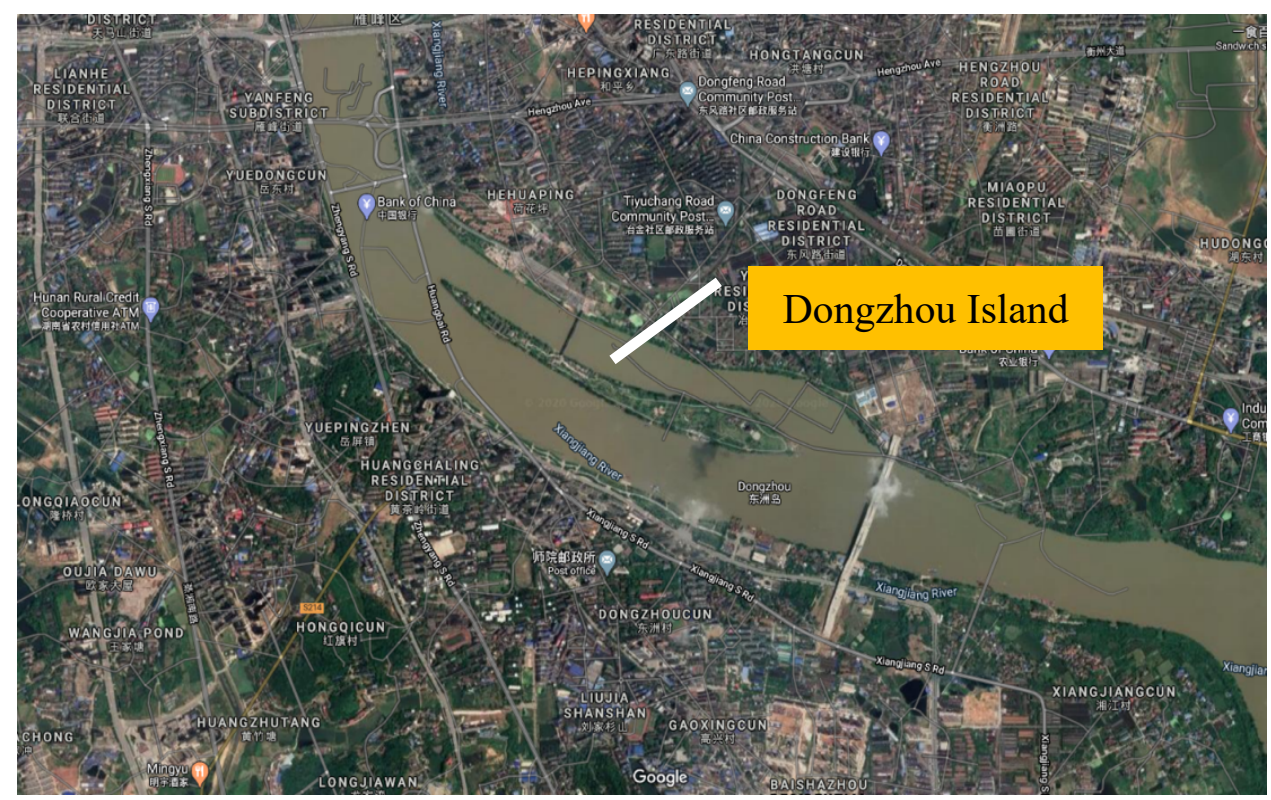

Figure 3 - Satellite image of Dongzhou Island in the Hengyang section of Xiangjiang River, a major tributary of the Yangtze threading through the territory of Hunan province.

(Source: Imagery @2020 TerraMetrics, DigitalGlobe, CNES/Airbus, Digital Globe, Map data @2020 Google)

These spatial practices overlap and clash with each other, also resulting in a series of tensions. Should a quasi-rural island be planned within or without the urban town? Should violence specific to island spatiality be heritagised within the framework of tourism? Should present recreational and economic needs be reconciled with the lived experiences and memories of former islanders?

The series of tensions summarised in the three cases profiled above are perhaps not unique to the specific kind of islands examined in this article. However, due to these river islands' transitional location in their parent cities and status of being discrete entities tightly surrounded by the mainland, these tensions tend to concretise more rapidly and radically, which is also symptomatic of the general trend of urbanisation in contemporary China. 


\section{A Critical-Holistic Approach}

No one-size-fits-all solution can be given with regard to the aforementioned tensions. For the moment, the least we can say is that inhabited river islands on the rural-urban fringe of inland China often exist at the intersection of complex relations and are subject to intense spatial reconfigurations. In the making and/or unmaking of these islands, several structural forces are in play including:

- localised island conditions resulting from fluvial processes (eg flooding, erosion, and sedimentation), island size, and distance from the urban mainland;

- a top-down power structure in which decisions concerning development are usually made;

- an entrenched urban-rural tension, manifested in the above cases in a spatial approach to urbanisation, gentrifying quasi-rural river islands and waterfront landscapes into lucrative real estate and visual-economic capital.

At the same time, several major fluid factors are also present, sometimes looming large but often invisible to the wider public, including:

- a civic need for and imagination of eco-cultural enclaves;

- the lived experiences and memories of island residents;

- traditional and new media imaginaries of island spaces.

Viewed individually, these forces and factors are perhaps not unique to the kind of river islands we examine. However, experientially speaking, their intense coexistence weaves an urban space consisting of different layers and strata usually insulated from each other. It is often the case that one or more of them will be more dominant than others in each concrete scenario. It is for this reason that I propose a critical-holistic approach to understanding the place-specific geographies of inhabited river islands on the rural-urban fringe of inland China. One of the primary challenges is to sort out the often confusingly vast array of imaginaries emanating from the island and to find theoretical and practical means of negotiating and contesting their relative statuses. It should be noted that island imaginaries are not symbolic figments floating above reality. On the contrary, they are often intertwined with island practice, constituting a loop of imaginative place-making.

Dongzhou Island for example, is relatively small and the distance to the city's urban core is neither as great as that of Chongming Island nor as negligible as that of Baguazhou. Effects of significant fluvial processes such as bank erosion have always been present, and flooding is a prominent phenomenon (although not necessarily perceived as a disastrous one) in both official chronicles and islanders' memories. These physical attributes constitute the foundation of the river island's identity. But so much else is subject to contextual variation. The local government used to regard it as a rural place on the rural-urban fringe of the city. This geographical subordination was translated into city dwellers' long-time perception of the island as an underdeveloped periphery. With the wave of urban expansion and tourism development starting from the mid-2ooos, the government began to re-appropriate Dongzhou's islandness, branding and manufacturing it into a postmodern mélange of ancient sanctity and modern recreation. Island histories of innocuous antiquity are recovered and reconstructed; it is a place of ancient wisdom and religious faith. More bloody ones have been left out; Japanese torture-killing in the autumn of 1944 has not been given a niche. As for lived island experiences, there is no way to recover them other than talk with displaced islanders, often of an older generation. Their geographical memories project the 
island, along with its riverine life, before extensive tourism development, as a place of ambiguities; it was at once poor and self-sufficient, idyllic and hellish, vulnerable and resilient, and liberating and confining (p.c. with anonymised islanders, 2018). A crucial challenge for river island scholarship is to find both theoretical and practical ways to account for this coexistence of imaginaries and do justice to the multiplicity of our geographical experiences.

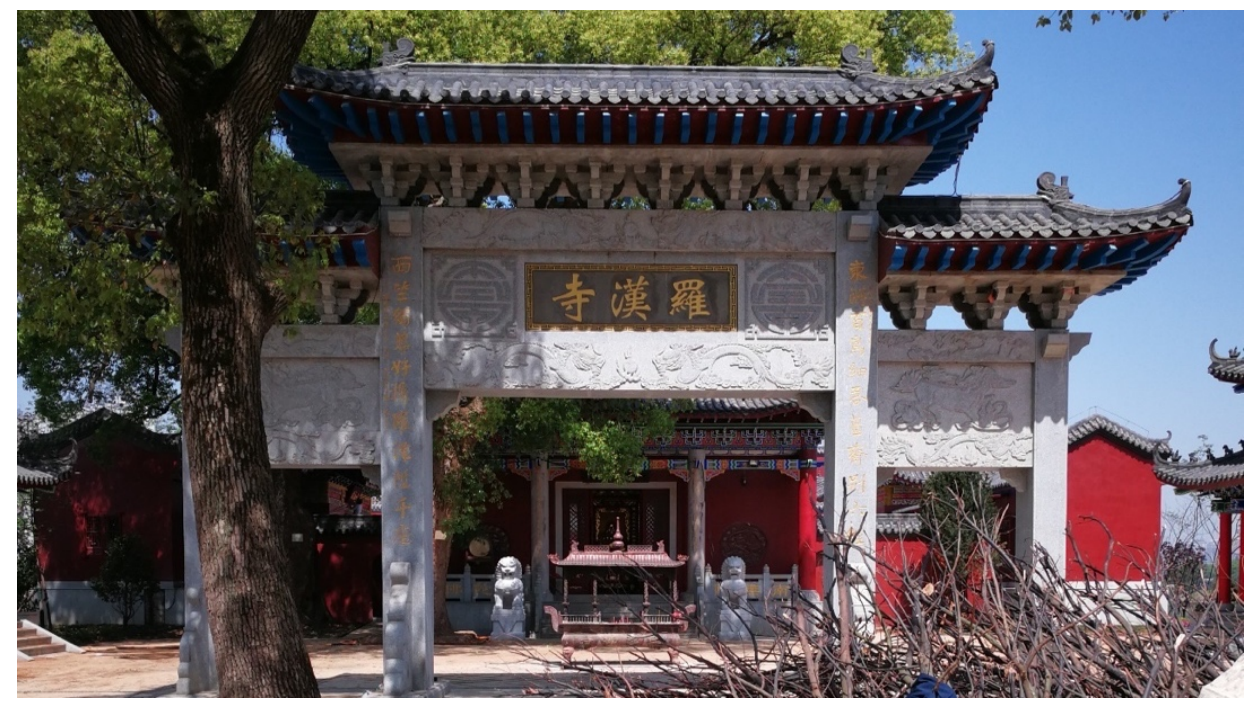

Figure 4 - A Buddhist temple being renovated at the northern tip of Dongzhou Island (author's photo, 2018).

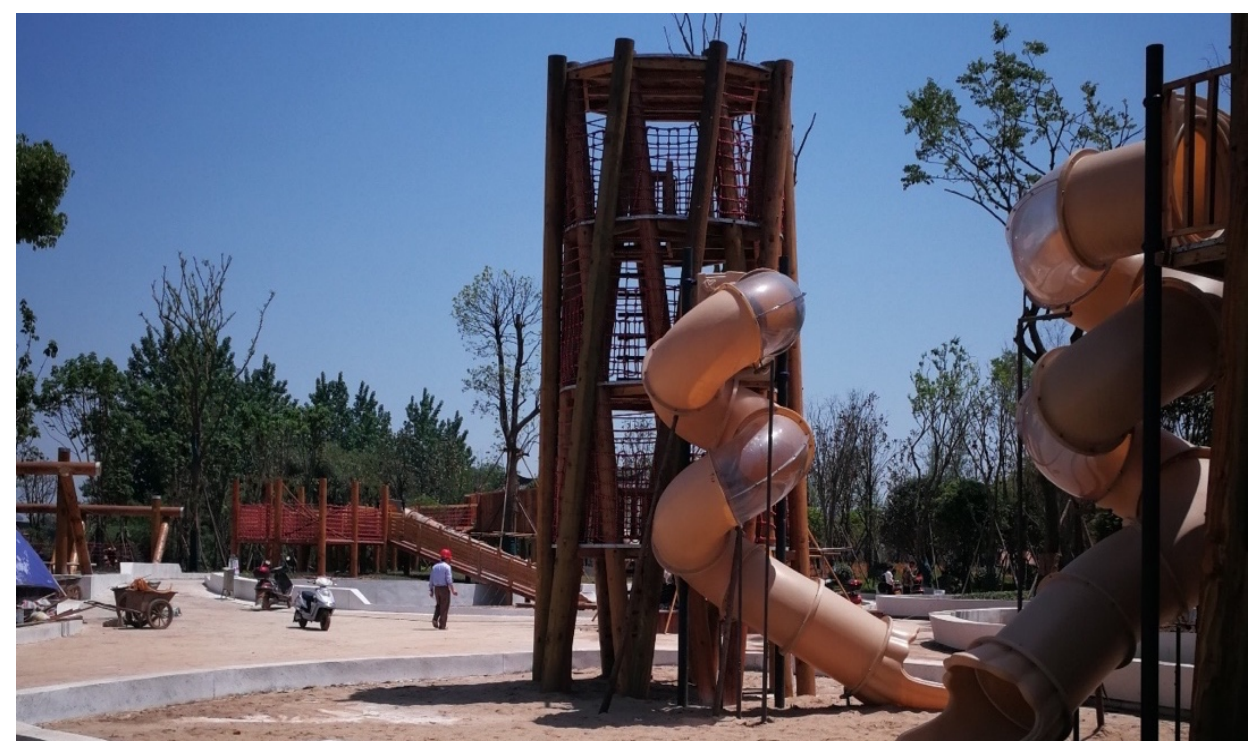

Figure 5 - A modern funfair project under construction near the southern tip of Dongzhou Island (author's photo, 2018). 
The imaginative place-making process taking place on Dongzhou has engendered multiple island imaginaries, overlapping, insulated from, and in conflict with each other. They include:

1) a living fossil embodying local identity and pride;

2) a green urban space symbolising a sustainable future;

3) a resource of gentrification and potential property price lifter;

4) an eco-space ruined by radical tourism development;

5) an authentic community displaced by radical tourism development;

6) a geographical witness of wartime violence;

7) a lived littoral community.

Some of these imaginaries are more visible than others and are embraced by mainly governmental and corporate interests but also some public ones, such as 1), 2), and 3) ( $\mathrm{Li}$, 2015; Li, 2011; Yi, 2011; Zou, 2013). Others can also be visible to the public, but only exist through vernacular outlets including articulations on social media and everyday communication, such as 4) and 5). It is only possible to retrieve the rest by delving into the more unsavoury aspects and the lived memories of the island's inhabited past (p.c with anonymised islanders, 2018). A critical-holistic approach to understanding the place-specific geographies of the island should take into account all the particular imaginaries, and, arguably, might be particularly addressed to the more obscure and invisible ones such as 6) and 7 ).

Similarly, the imaginative place-making process taking place on Baguazhou has also engendered multiple island imaginaries including:

1) a quasi-rural backwater rejuvenated by economic liberalisation;

2) a traditional rice supply base for mainland Nanjing;

3) an innovated vegetable supply base for mainland Nanjing;

4) a littoral space plagued by Schistosomiasis;

5) a pristine place affected by pollution and disrupted by urbanisation;

6) a vulnerable piece of land in the water under the constant threat of flood;

7) a green tourism spot signifying a modern and sustainable future for the city.

A critical-holistic approach to understanding the place-specific geographies of Baguazhou should also take into account all of the particular imaginaries, and might be best focussed on the more obscure and invisible ones such as 5) and 6) (Cui and Yan, 2020; Song et al, 2017; Yap and Li, 2016; Yuan et al, 2015; Zhou, 1997).

Surprisingly, I found a serious engagement with the less visible imaginaries of Baguazhou in the work of a local fiction writer rather than in academic literature. Cao Kou was born in the late 1970 and had lived on Baguazhou Island before going into college and eventually making a living as a teacher on the more urbanised south bank of Nanjing. This is, to some extent, the epitome of the life trajectory of more educated islanders in inhabited, urban river islands; the island is the opposite of urbanism, an economic and cultural backwater to escape from. The mood of gloom and despondency resulting from the marginal and dependent existence of the river island to and on the urban mainland is illustrated in one of Cao Kou's memoirs about his teenage years when he and his brother had to wake up early every day to wait for the ferry to take their agricultural produce to the other side of the Yangtze to be sold. Nevertheless, the island also carries positive memories. It functions, in the mind of island expats like Cao Kou at least, as a largely innocent existence that precedes the hectic

Shima Volume 14 Number 22020

-160 - 
and alienating rhythm of the modern city. Its innocence is remembered as intimate family life and a bond with nature. Echoing a critical concern with the evaluation of fixed links for islands in island studies, Cao Kou dwelled on the impact of the building of the No.2 Yangtze Bridge on the island community in one of his works. His tone is nostalgic, and his stance is negative; the bridge has disrupted the equilibrium of the community, resulting in cultural loss and structural shakeup (2012: 158-159; 2013: 99-103). Writers are generally more sensitive to societal changes. In this regard, Cao Kou did not say much on the material benefits that the bridge has brought to the island. A more comprehensive assessment of the interplay between modern connectivity and island life should take into consideration diverse sources of representation, and ultimately reach a critical-holistic understanding (although a writer has every right to dwell on only one slice of life and magnify it into their own vision of a place).

\section{Conclusion}

The article starts with a critical review of Island Studies' recent engagement with Chinese islands and archipelagos. After a plea for the necessity to incorporate inhabited river islands on the rural-urban fringe of inland China within the scope of the field, the article takes a brief detour to summarise the treatment of river islands as living fossils by branches of physical geography in order to pave the way for a socio-cultural approach towards studying river islands as lived communities. The main body of the article presents and analyses three cases from inland China before proposing a critical-holistic approach to understanding the local geographies of these islands. The plethora of imaginaries and tensions revealed in the analysis have to do with the place-specific geographies of these islands.

Like non-riverine ones, inhabited river islands on the rural-urban fringe of inland China have place-specific geographies. Indeed, it could even be argued that in some regards they are even more place-specific than non-riverine ones. As far as my case studies go, these particular types of river island are characterised by a paradoxical geography of super-connectedness and utter-unconnectedness, meaning that on the one hand they are more assimilated into mainland environments (unanimously also administrated by a mainland municipal state) while on the other their existence is also discrete in the sense that they are usually disparate communities dotted in rivers unable to form a larger collectivity with other kindred islands. This paradox partly has to do with the natural geography of these islands and partly with the domestic political structure; it is at once natural and social.

In the problématique of Island Studies, the status of being super-connected has several implications. For one thing, these islands tend to be more susceptible to radical innovations and infrastructural projects due to a heightened perception and easy manoeuvrability of their spatialities. In a way, they could be seen as the Anthropocene writ large (see Zalasiewicz et al, 2019: 2; Crutzen and Stoermer, 2000; Crutzen, 2002 for geological definitions of the Anthropocene; also see Pugh, 2018; Vitousek and Chadwick, 2013; Hayward, 2018 for islandcentred interpretations of the concept). In another way, their relative accessibility could mean that these islands have the potential to benefit from urbanisation. Nonetheless, no easy evaluation can be made in this regard. Many differentials need to be taken into account including generation, social class, gender etc. In the meantime, the status of being utterly unconnected with kindred islands in the fluvial system could have both philosophical and real-world implications. Though researchers from Island Studies have taken a minimal interest in river islands, it is unlikely that any would deny their status of being islands. What is more pertinent to the problématique of Island Studies is that it is difficult to imagine the 
particular kind of river islands examined in this article within a bigger non-mainland unit, such as an archipelago ${ }^{4}$. The difficulty of imagining such islands as parts of archipelagos could also perhaps explain partially Island Studies' lack of enthusiasm for river islands considering the discipline's advocacy of an organic and empowering perception and understanding of islands in terms of "our sea of islands" rather than as "islands in a far sea" (Hau'ofa, 1993). Viewed through this lens, the islandness of single islands dotted in rivers is perhaps too disparate, that is, they lack the agency to form an archipelagic community with sufficient autonomy in politico-economic and even cultural terms. This 'real-world' implication of this particular kind of river islands' discrete condition brings us to the issue of empowerment.

Many subnational island jurisdictions (including those few in the Sinophone world) that show inclinations to autonomy are essentially resorting to identity politics as a major resistance and development strategy in face of the perceived threat of homogenisation (see Yuen and Cheng, 2020). The kind of inhabited river islands examined in this article should be different. They are much smaller, more discrete, lacking the agency to form a bigger nonmainland collectivity and, at best, semi-enclaves existing in the fuzzy zone of rural-urban divide (or connection) of inland China where landscapes metamorphosise rapidly. Though they are also under the threat of homogenisation brought about by relentless urban expansion and innovation often spearheaded by external actors, identity politics is a solution that is not easily applicable to these communities. If anything, diverse forms of identity culture seem like a more viable, and also urgently needed, alternative. The recuperation of heterogenous island histories and experiences is beneficial for both the island and the city. In contradistinction to politics, culture constitutes a realm of "relative autonomy" because though it is "conditioned materially", in turn it is also "constitutive of social order" (Kane, 1998: 74). Despite their propensity towards misrepresentation and even distortion often driven by an insatiable demand for ever greater traffic and ever more attention, new media and other civic outlets may still be a most promising agent for change.

To end, I would like to propose a few potential benefits for Island Studies of studying the particular kind of river islands profiled in this article. For one thing, studying non-maritime islands can provide the discipline with a bigger playing field. While oceanic islands and archipelagos may still be the focal point, limiting research to these areas is epistemologically and ethically unsatisfactory. More importantly, the particular spatialities of inhabited river islands provided in this case invite a rethink of aspects of islandness in local manifestations. Admittedly, islandness will still play a key role in theorisation of these island geographies. But the trait of being tightly surrounded by the mainland presents non-island variables that are often at work in conjunction with stock aspects of islandness (Kelman, 2020). In this regard, through the mirror image of the nontypical, the typical could perhaps have a fuller grasp of its own self.

\footnotetext{
4 This is an incidental lesson taught during the peer review process for this article. One of the referees of an earlier draft of this article suggested that the distinctiveness of river islands in relation to other kinds of islands that are commonly studied within Island Studies is that river islands are "typically tightly surrounded by the mainland" and this somehow "mitigates against their being imagined as parts of archipelagos". I had difficulty understanding the latter part of the remark at first because imagining islands as parts of archipelagos would not be the immediate response of a Chinese who, despite being a longtime resident in an archipelagic area, is so accustomed to continental mindset that he sees only mainland/islands, rather than archipelagos. I cannot speak for all, but I believe this is the typical mindset of most Chinese living in inland areas. This misaligned perception of islands and archipelagoes could also serve as an initiation into more cross-cultural comparative work on islandness.
} 


\title{
Gang - Chinese River Islands
}

\begin{abstract}
This research article was supported by the General Program of the National Social Science Fund of China [Grant No. 19BWW090]. <此研究论文受到中华社会科学基金资助（批准 号：19BWW090），为 2019 年度国家社会科学基金项目（一般项目）阶段性成果>
\end{abstract}

\section{BIBLIOGRAPHY:}

Bi, J (2003) ‘Baguazhou luhaoqiaoshitanyuan', Jiangsu Rural Economy v5: 28-29

Blitz, B. K (2014) 'Location security and environmental-induced displacement: a case study of the riverine islands in Bangladesh', Refuge v29 n2: 63-71

Cao, K (2013) Shenghuo pian, Chongqing: Chongqing University Press

Cao, K (2012) Shiqi Nianbiao, Nanchang: Baihuazhou Literature and Art Press

Chao, Y and Chao, S (2017) 'Resident and visitor perceptions of island tourism: green sea turtle ecotourism in Penghu archipelago, Taiwan', Island Studies Journal v12 n2: 213-228

Chen, H, Wu, J and Li, Y (2009) 'Application of tetrahedron with six sides in levee foot consolidation of Baguazhou reach of the Yangtze River', Yangtze River v40 n5: 71-73

Chi, Y, Wang, E and Wang, J (2020) 'Identifying the Anthropogenic influence on the spatial distribution of plant diversity in an estuarine island through multiple gradients', Global Ecology and Conservation v21:

https://www.sciencedirect.com/science/article/pii/S2351989419304986 - accessed 2nd July 2020

Coupe, S (2001) 'Project overview and findings - Project R8103: consensus for a holistic approach to improve rural-livelihoods in riverine-islands of Bangladesh,' UK Department for International Development:

https://assets.publishing.service.gov.uk/media/57ao8c9ce5274a27b20012eb/R8103AnnA.pdf - accessed 2nd July 2020

Crocombe, R (2009) 'China and USA in the Pacific and the Caribbean: whose incursion, whose territory? A brief rejoinder to McElroy and Bai', Island Studies Journal v4 nı: 99-10o

Crutzen, P.J (2002) 'Geology of Mankind', Nature v415: 23

Crutzen, P.J and Stoermer, E. F (2000) 'The “Anthropocene”, Global Change Newsletter v41: 17-18

Cui, J, Li, Z, Liu, Z, Ge, B, Fang, C, Zhou, C and Tang, B (2014) 'Physical and chemical stabilization of soil organic carbon along a 500-year cultivated soil chronosequence originating from estuarine wetlands: temporal patterns and land use effects', Agriculture, Ecosystems and Environment v196: 10-20 


\section{Gang - Chinese River Islands}

Cui, Z and Yan, Y (2020), 'A GIS-based research on the spatial evolution characteristics and influence mechanism of the rural settlements in city island: a case study of Baguazhou in Nanjing', Modern Urban Studies v2: 90-97

Diamond, J (2017) Guns, germs, and steel: the fates of human societies, New York: Norton

Elmahal, A.E and Abdalla, A (2017) 'Assessing the impacts of bridges on the development of fluvial islands using remote sensing and GIS: case study on the islands of Khartoum State up to Sabaloka Gorge, Khartoum State, Sudan', World Academy of Science, Engineering and Technology International Journal of Geological and Environmental Engineering v4 n7: 105-111

Fan, X and Zhang, L (2012) 'Spatiotemporal dynamics of ecological variation of waterbird habitats in Dongtan area of Chongming Island', Chinese Journal of Oceanology and Limnology v30 n3: 485-496

Grydehøj, A and Kelman, I (2016) 'Island smart eco-cities: innovation, secessionary enclaves, and the selling of sustainability', Urban Island Studies v2: 1-24

Hau'ofa, E (1993) 'Our sea of islands', The Contemporary Pacific v6 n1: 148-161

Hay, P (2013) 'What the Sea portends: a reconsideration of contested island tropes', Island Studies Journal v9 n2: 209-232

Hayward, P (2016) 'Tanka transitions: shrimp paste, dolphins and the contemporary aquapelagic assemblage of Tai O', Locale: The Australasian-Pacific Journal of Regional Food Studies n6: 1-19

Hayward, P (2018) 'Keynote: formulations in flux', archipelagos and aquapelagos conceptualising islands and marine spaces,' keynote address to Archipelagos and Aquapelagos conference, Pratt Institute, Brooklyn, 3oth March-1st April

Hong, G (2017) 'Locating Zhuhai between land and sea: a relational production of Zhuhai, China, as an island city', Island Studies Journal v12 n2: 7-24

Hong, Q, Zhang, Q and Yu, B (1999) 'Gaigekaifang Huajiangzhou', Reform and Opening nı: 17-18

Kane, A (1998) 'Analytic and concrete forms of the autonomy of culture', in Smith, P (ed) The new American cultural sociology, New York: Cambridge University Press: 73-88

Kelman, I (2020) 'Islands of Vulnerability and Resilience: Manufactured Stereotypes?', Area v52 n1: 6-13

Kenward, S, Pritchard, M and Hannan, M (2015) 'Resilient livelihoods: CLP's multi-sectoral approach to promoting livelihoods and reducing poverty in the Chars', Chars Livelihoods Programme - research report, London: Department for international Development

Kwong, Y and Wong, M.Y.H (2017) 'State size and democratization in hybrid regimes: the Chinese island cities of Macau and Hong Kong', Island Studies Journal v12 n2: 113-126 
Lahiri-Dutt, K (2014) 'Chars: islands that float within rivers', Shima: The International Journal of Research into Island Cultures v8 n2: 22-38

Lee, S, Huang, W and Grydehøj, A (2017) 'Relational geography of a border island: local development and compensatory destruction on Lieyu, Taiwan', Island Studies Journal v12 n2: 97-112

Leung, A, Tanko, M, Burke, M and Shui, C.S (2017) 'Bridges, tunnels, and ferries: connectivity, transport, and the future of Hong Kong's outlying islands', Island Studies Journal v12 n2: 6182

Li, S, Huang, B, Zhao, F et al (2019) 'Environmental Impact Assessment of Agricultural Production in Chongming Ecological Island', The International Journal of Life Cycle Assessment v24 n11: 1937-1947

Li, S (2015) ‘Quanlidazaohao Zheyichengshimingpian’, Hengyang Daily 26th March: 1

Li, S (2016) 'The Transformation of island city politics: the case of Macau', Island Studies Journal v11 n2: 521-536

Liu, Z, Fan, B, Huang, Y et al (2019) 'Assessing the ecological health of the Chongming Dongtan nature reserve, China, using different benthic biotic indices', Marine Pollution Bulletin v146: 76-84

Li, Y (2011) ‘Dongzhoudaoguihuajianshe Jiangtishangrichen', Hengyang Daily, 22nd April: 2

Ma, Z, Dong, T, Liao, W et al (2019) 'Ciliates in the marsh wetlands of Chongming island: taxonomy of five species and a species list', Journal of Ocean University of China v18 n2: 441454

McElroy, J.L and Bai, W (2008) 'The political economy of China's incursion into the Caribbean and Pacific', Island Studies Journal v3 n2: 225-246

Merriam-Webster (nd) 'Living fossil', Merriam-Webster Dictionary: https://www.merriamwebster.com/dictionary/living\%2ofossil - accessed nth May 2020

Misra, P.J (2011) 'Risk-factor assessment for non communicable diseases amongst a tribal community living in the riverine islands of the River Brahmaputra in Assam' (unpublished) dissertation for the degree of Master of Public Health, Sree Chitra Tirunal Institute for Medical Sciences and Technology Trivandrum, India

Ni, S, Tang, U.W and Grydehøj, A (2017) 'Urban morphology and urban fragmentation in Macau, China: island city development in the Pearl River Delta megacity region', Island Studies Journal v12 n2: 199-212

Osterkamp, W.R (1998) 'Processes of fluvial island formation, with examples from Plum Creek, Colorado and Snake River, Idaho', Wetlands v18 n4: 530-545

$\mathrm{Ou}, \mathrm{Z}$ and Ma, G (2017) 'Marginalisation of the Dan fishing community and relocation of Sanya fishing port, Hainan Island, China', Island Studies Journal v12 n2: 143-158 


\section{Gang - Chinese River Islands}

Picco, L, Mao, L, Rainato, R and Lenzi, M.A (2013) 'Medium-term fluvial island evolution in a disturbed gravel-bed river (Piave River, Northeastern Italian Alps)', Geografiska Annaler: Series A, Physical Geography v96 nı:

https://www.tandfonline.com/doi/full/10.1111/geoa.12034?scroll=top\&needAccess=true accessed 4th July 2020

Picco, L, Tonon, A, Ravazzolo, D and Rainato, R (2014) 'Monitoring river islands dynamics using aerial photographs and lidar data: the Tagliamento River study case', Applied Geomatics 7: 163-170

Planningtank (nd) Rural urban fringe: concept, history, reasons, issues: https://planningtank.com/settlement-geography/rural-urban-fringe - accessed 2nd July 2020

Platt, S.R (2007) Provincial patriots: the Hunanese and Modern China, Cambridge: Harvard University Press

Pritchard, M, Kenward, S and Hannan, M (2015) 'Climate change and resilient livelihoods: CLP's approach to reducing the vulnerability of the extreme poor in the riverine islands of North-West Bangladesh', Chars Livelihoods Programme - research report, London: Department for international Development

Pugh, J (2018) 'Relationality and Island Studies in the Anthropocene', Island Studies Journal v13 n2: 93-110

Qin, Y and Li, S (2019) 'Ecological health evaluation and ecotourism resources improvement countermeasures in Nanjing Riverside Wetlands', Ecological Science v38 n4: 150-157

Qiu, S, Yue, W, Zhang, H and Qi, J (2017) 'Island ecosystem services value, land-use change, and the national new area policy in Zhoushan archipelago, China', Island Studies Journal v12 n2: $177-198$

Solimine, K (2013) 'Harmony and Chongming Island: conserving nature in the shadow of the megalopolis', The World of Chinese v3: 52-55

Song, J, Zhu, Q, Jiang, X et al (2017) 'GIS-Based heavy metals risk assessment of agricultural soils: a case study of Baguazhou, Nanjing’, Acta Pedologica Sinica v54 n1: 81-91

$\mathrm{Su}, \mathrm{M}$, Wall, G and Wang, S (2017) 'Yujiale fishing tourism and island development in Changshan archipelago, Changdao, China', Island Studies Journal v12 n2: 127-142

$\mathrm{Su}, \mathrm{P}$ (2017) 'The floating community of Muslims in the island city of Guangzhou', Island Studies Journal v12 n2: 83-96

Ueda, M (2014) Haiyudiguo: Mingqingshidai (translated by Gao, Y) Guilin: Guangxi Normal University Press

Vickers, M. (2012) Eyots and Aits: islands of the River Thames, Stroud: The History Press 


\section{Gang - Chinese River Islands}

Vitousek, P and Chadwick, O (2013) 'Pacific Islands in the Anthropocene', Elementa: Science of the Anthropocene:

https://www.elementascience.org/articles/10.12952/journal.elementa.ooool1/ - accessed 4th July 2020

Wang, Q, Tan, J, Wu, J et al (2013) 'Assessment of soil quality of tidal marshes in Shanghai city', Asian Agricultural Research v5 n9: 94-99

Wang, Y, Yang, C, Zou, L and Cui, H (2015) 'Spatial distribution and fluorescence properties of soil dissolved organic carbon across a riparian buffer wetland in Chongming island, China', Pedosphere v25 n2: 220-229.

Wintenberger, C, Rodrigues, S, Bréhéret, J and Villar, M (2015) 'Fluvial islands: first stage of development from nonmigrating (forced) bars and woody-vegetation interactions', Geomorphology v246: 305-320

$\mathrm{Wu}, \mathrm{X}, \mathrm{Gu}, \mathrm{J}, \mathrm{Lin}, \mathrm{C}$ and $\mathrm{Wu}, \mathrm{Y}$ (2004) 'Analysis on Tourism Development of Baguazhou Island', Areal Research and Development v4: 64-67

Wyrick, J. R and Klingeman, P. C (2011) Proposed fluvial island classification scheme and its use for river restoration, River Research and Applications n27: 814-825

Xie, L, Flynn, A, Tan-Mullins, M and Cheshmehzangi, A (2019) The making and remaking of ecological space in China: the political ecology of Chongming Eco-Island', Political Geography v69: 89-102

Yi, C (2011) ‘Dongzhoutaolangnuan Yimengsibainian', Hengyang Daily November 25th: 2

Yuan, S and Cheng, E.W (2020) 'Between high autonomy and sovereign control in a subnational island jurisdiction: the paradox of Hong Kong under "One Country, Two Systems"', Island Studies Journal v15 n2: 131-150

Yu, C, Huang, Y, Yeh, P and Chao, P (2017) 'Residents' attitudes toward island tourism development in Taiwan', Island Studies Journal v12 n2: 159-176

Yue, W, Qiu, S, Zhang, H and Qi, J (2017) 'Migratory patterns and population redistribution in China's Zhoushan archipelago in the context of rapid urbanization', Island Studies Journal v12 n2: 45-6o

Zalasiewicz, J, Waters, C.N, Williams, M and Summerhayes, C (eds) (2019) The Anthropocene as a geological time unit, Cambridge: Cambridge University Press

Zhan, J, Zhang, F, Chu, X, et al (2019) 'Ecosystem services assessment based on emergy accounting in Chongming Island, Eastern China', Ecological Indicators n105: 464-473

Zheng, R, Zhao, J, Zhou, X et al (2016) 'Land use effects on the distribution and speciation of heavy metals and arsenic in coastal soils on Chongming Island in the Yangtze River estuary, China', Pedosphere v26 n1: 74-84

Zou, X (2013) “'Beidaqingniao” yudazao hengyanglvyou "Shengjiban”, Hengyang Daily September 4 th: 1 